\title{
Influence of Loosely Bound Water on Compressibility of Compacted Fine-Grained Soils
}

\author{
Rui Zhang $\mathbb{D}^{1,2}$ Mengli Wu, ${ }^{2}$ Prince Kumar, ${ }^{3}$ and Qian-Feng Gao $\mathbb{i}^{1,2}$ \\ ${ }^{1}$ National Engineering Laboratory of Highway Maintenance Technology, Changsha University of Science \& Technology, \\ Changsha 410114, China \\ ${ }^{2}$ School of Traffic \& Transportation Engineering, Changsha University of Science \& Technology, Changsha 410114, China \\ ${ }^{3}$ Graduate Research Assistant, Zachry Department of Civil \& Environment Engineering, Texas A\&M University, College Station, \\ Texas 77843, USA
}

Correspondence should be addressed to Rui Zhang; zr@csust.edu.cn

Received 24 August 2019; Revised 31 December 2019; Accepted 3 February 2020; Published 22 February 2020

Academic Editor: Claudia Vitone

Copyright (c) 2020 Rui Zhang et al. This is an open access article distributed under the Creative Commons Attribution License, which permits unrestricted use, distribution, and reproduction in any medium, provided the original work is properly cited.

This study aimed to investigate the influence of loosely bound water (LBW) on the compressibility of compacted fine-grained soils and accurately determine the soil's compression index. Four fine-grained soils (i.e., heavy clay, heavy silt, lean clay, and lean silt) and a coarse-grained soil were examined. The volumetric flask method was used to measure the LBW contents of the five soils. $\mathrm{X}$-ray diffraction (XRD) analysis was then performed to test the mineral compositions and help explain the reason why the LBW content varied between different soils. A concept of modified void ratio was proposed by assuming that LBW is a part of the solid phase in soil. Subsequently, consolidation tests and permeability tests were conducted on saturated compacted specimens. The results show that the compression indexes or permeability coefficients tend to be the same for the soils with identical initial modified void ratios. Consolidation tests were also carried out on the unsaturated compacted heavy silt of four different dry densities prepared at a water content higher than the optimum. They show that the compression of unsaturated soil occurs if pore air is discharged when the water content is less than the LBW content. This confirms the previous assumption that LBW can be regarded as a part of the soil solid phase. A modified compression index was deduced and implemented to predict the settlement of a road embankment. The result suggests that the modified compression index is capable of calculating the compression of finegrained soils, whose water contents are higher than their LBW contents.

\section{Introduction}

Fine-grained soils are commonly encountered in the practice of geotechnical engineering, making it crucial to understand and predict their engineering behaviors, which are strongly dependent on water contents. Previous studies have shown that the water-holding capacity of soil affects its compression characteristics $[1,2]$, and the loosely bound water (LBW), the main form of water in fine-grained soil $[3,4]$, affects the microstructure during the compression process. Soil compression characteristics have consistently been the focus of attention in engineering design and construction, as the postconstruction soil settlement significantly affects the safety and stability of superstructures. Therefore, it is theoretically and practically important to study the effect of LBW on soil compression characteristics.

The compression of soil is a process that involves the dissipation of pore water and air, particle movements, and increased densities under the actions of loads [5]. The soil compressibility can be characterized by the compression index $\left(C_{c}\right)$. An accurate determination of $C_{c}$ is required for a better understanding of the mechanical properties of soil. The void ratio that greatly affects the compression process of soil is a key parameter in the determination of $C_{c}[6,7]$. Petersen et al. [8] found that the $C_{c}$ value of clay was smaller than that of silt at the same initial void ratio. Chu et al. [9] pointed out that the mineral composition of soil affected the soil compressibility. Sridharan and Jayadeva [10] presented 
that $C_{c}$ was related to the specific surface area of soil particles. In the literature, many experimental and microstructural observations revealed that the consolidation and compression processes of soil were also affected by LBW $[11,12]$. According to the diffuse-electric double layer (DDL) theory [13], the water in soil can be classified into three types, i.e., tightly bound water (TBW), LBW, and free water. TBW is tightly adsorbed on the surfaces of soil particles, and it gradually turns into LBW with weakening action of the electric double layer. TBW has a strong viscosity and cannot be removed entirely from the surfaces of soil particles until the soil temperature is raised up to $200^{\circ} \mathrm{C}$. Because of its unique properties, TBW is generally incorporated as a part of soil particles in calculations [14].

Many studies, including nanoscale observations, have revealed that the density of LBW was higher than that of free water [15-17]. It was found that the LBW content of finegrained soils was generally between $0.3 \%$ and $5.0 \%$ and the LBW density ranged from $1.15 \mathrm{~g} / \mathrm{cm}^{3}$ to $1.872 \mathrm{~g} / \mathrm{cm}^{3}$ $[14,18,19]$ and gradually became lower as the distance from the particle surface increased [20]. The montmorillonite content of soil also greatly affected the content and density of LBW [21-24]. Various studies reported different values for the LBW density but failed to suggest a fixed value. LBW could be converted into free water at temperatures above $50^{\circ} \mathrm{C}$ [17]. By oedometer tests, Shang et al. [25] observed that the soil water content approximated the LBW content at a consolidation pressure of $2 \mathrm{MPa}$. Furthermore, many researchers found that the DDL efficiently explained the consolidation behavior of soil [26-29]. The isomorphous substitution of clay minerals occurs easily in fine-grained soils, and low valence ions replace high valence ions, resulting in a loss of positive and negative charges on the surfaces of clay minerals. Cations and dipole water molecules are adsorbed on the surfaces of soil particles due to static electricity, which cannot easily discharge under external forces [18]. In the process of consolidation, the existence of the LBW film greatly reduces the soil permeability.

To the best of our knowledge, few studies have addressed the effect of LBW on the compressibility of soil. Therefore, one objective of this study was to determine the LBW contents of different fine-grained soils using the volumetric flask method and then to analyze the effects of LBW on the consolidation characteristics of soil specimens. The second objective was to propose a modified mathematical equation for the void ratio considering the LBW effects. Subsequently, the modified compression index $\left(C_{c}^{\prime}\right)$ was calculated by the proposed equation and compared with the conventional $C_{c}$ value and the theoretical value determined based on the work of Sridharan and Jayadeva [10]. Finally, the settlement of a road embankment was predicted using $C_{c}^{\prime}$ and verified with field data.

\section{Modification of Void Ratio}

Since LBW is usually hard to remove from soil $[25,30]$, it can be regarded as a part of the solid phase in soil when the water content is greater than the LBW content. In this study, the assumption is also made to deduce the modified void ratio.
Thus, the three-phase structure of soil can be illustrated in Figure 1. The LBW content is defined as

$$
w_{g}=\frac{m_{g}}{m_{s}}
$$

where $w_{g}$ is the LBW content, $m_{g}$ is the LBW mass, and $m_{s}$ is the solid mass of soil.

Then, the volume of LBW can be calculated by

$$
V_{g}=\frac{m_{g}}{\rho_{g}}=\frac{\rho_{s}}{\rho_{g}} V_{s} \cdot w_{g},
$$

where $V_{g}$ is the LBW volume, $\rho_{g}$ is the LBW density, $\rho_{s}$ is the density of the soil solid, and $V_{s}$ is the solid volume of the soil.

Thus, the volume of the soil solid phase including LBW $\left(V_{s}^{\prime}\right)$ can be calculated by

$$
V_{s}^{\prime}=V_{s}+V_{g}=V_{s}\left(1+\frac{\rho_{s}}{\rho_{g}} w_{g}\right) \text {. }
$$

According to the definition of void ratio, the modified void ratio that takes LBW into account can be calculated by

$$
e^{\prime}=\frac{V}{V_{s}^{\prime}}-1=\frac{V_{s}(e+1)}{V_{s}^{\prime}}-1,
$$

where $e^{\prime}$ is the modified void ratio and $V$ is the total volume of the soil.

Substituting $V_{s}^{\prime}$ from equation (3) into (4) yields the expression of the modified void ratio:

$$
e^{\prime}=\frac{e+1}{1+\left(\rho_{s} / \rho_{g}\right) w_{g}}-1 .
$$

\section{Experimental Program}

3.1. Soil Samples. Four fine-grained soil samples were collected from different cities in China: Xiangtan, Danzhou, Zhuzhou, and Enshi. A coarse-grained soil sample was selected from Changsha for comparison purposes. Particle size analyses, Atterberg limit tests, and specific gravity tests were performed on all of the soil samples. The methylene blue adsorption method was employed to determine the specific surface area of soil particles [31]. The basic physical properties of the soils are shown in Table 1. The soil samples were classified as per ASTM D2487: Xiangtan soil was heavy clay $(\mathrm{CH})$, Danzhou soil was heavy silt $(\mathrm{MH})$, Zhuzhou soil was lean clay (CL), Enshi soil was lean silt (ML), and Changsha soil was clayey sand (SC).

3.2. X-Ray Diffraction Tests. XRD was used to identify the clay minerals in different soils $[32,33]$. The collected soil samples were dried and pulverized to obtain homogeneous powders (less than $40 \mu \mathrm{m}$ ), and the angle was set from $3^{\circ}$ to $80^{\circ}$. The test results were characterized by the X-ray diffraction pattern, from which different minerals (e.g., illite, kaolinite, montmorillonite, and quartz) were identified by matching the peaks to the known database of minerals. The matching process and the mineral quantification were realized using the Match 3 XRD software. 


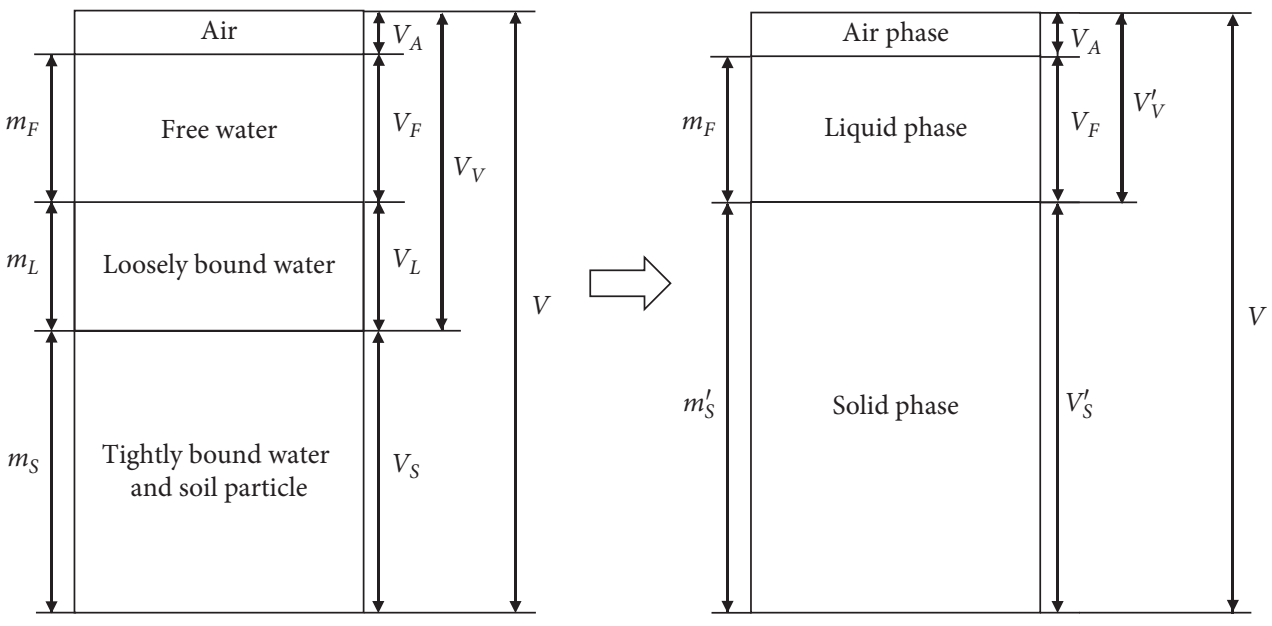

FIGURE 1: Three-phase schematic diagram of soil considering LBW.

TABle 1: Physical properties of different soil samples.

\begin{tabular}{|c|c|c|c|c|c|c|c|c|c|c|}
\hline \multirow[b]{2}{*}{$\begin{array}{l}\text { Collection } \\
\text { site }\end{array}$} & \multicolumn{3}{|c|}{$\begin{array}{c}\text { Particle } \\
\text { composition (\%) }\end{array}$} & \multirow{2}{*}{$\begin{array}{c}\text { Specific } \\
\text { surface area } \\
\left(\mathrm{m}^{2} \cdot \mathrm{g}^{-1}\right)\end{array}$} & \multirow[b]{2}{*}{$\begin{array}{l}\text { Natural water } \\
\text { content }(\%)\end{array}$} & \multicolumn{3}{|c|}{ Atterberg limit } & \multirow[b]{2}{*}{$\begin{array}{l}\text { Specific } \\
\text { gravity }\end{array}$} & \multirow[b]{2}{*}{$\begin{array}{l}\text { United soil } \\
\text { classification }\end{array}$} \\
\hline & Clay & Silt & Sand & & & $\begin{array}{l}\text { Liquid } \\
\text { limit } w_{l} \\
\quad \%)\end{array}$ & $\begin{array}{l}\text { Plastic } \\
\text { limit } w_{p} \\
\quad \%)\end{array}$ & $\begin{array}{c}\text { Plasticity } \\
\text { index PI (\%) }\end{array}$ & & \\
\hline Xiangtan & 50.80 & 40.98 & 8.22 & 50.34 & 26.4 & 69.9 & 33.4 & 36.5 & 2.71 & $\mathrm{CH}$ \\
\hline Danzhou & 48.00 & 32.50 & 19.50 & 40.78 & 36.1 & 57.2 & 31.3 & 25.9 & 2.73 & $\mathrm{MH}$ \\
\hline Zhuzhou & 40.41 & 24.52 & 35.07 & 26.91 & 18.7 & 46.7 & 23.6 & 23.1 & 2.66 & CL \\
\hline Enshi & 25.77 & 40.01 & 34.22 & 24.47 & 24.75 & 31.01 & 19.2 & 12.32 & 2.75 & ML \\
\hline Changsha & 7.76 & 20.12 & 72.12 & 20.39 & 21.2 & 29.8 & 15.6 & 14.2 & 2.69 & SC \\
\hline
\end{tabular}

3.3. LBW Content Tests. The surfaces of soil particles contain hydroxyl and oxide layers. Water molecules pass through the hydrogen bonding, van der Waals forces, ion exchange, etc. and form a water film when they meet the bound water. Researchers have determined the LBW density at different soil water contents. It was reported that the LBW densities of soil were $1.46 \mathrm{~g} / \mathrm{cm}^{3}, 1.27 \mathrm{~g} / \mathrm{cm}^{3}$, and $1.16 \mathrm{~g} / \mathrm{cm}^{3}$ at water contents of $15 \%, 28 \%$, and $46 \%$, respectively [19]. Generally, in road embankments, the water content is between $15 \%$ and $28 \%$ for fine-grained soils. Thus, an LBW density of $1.3 \mathrm{~g} / \mathrm{cm}^{3}$, which was the same as that suggested by Kurichetsky and Li [34], was tentatively assumed in this study. $\mathrm{Wu}$ [13] proposed the volumetric flask method to determine the LBW content. In this method, the density of free water in clay is assumed to be $1.0 \mathrm{~g} / \mathrm{cm}^{3}$. After the free water is transformed into LBW, the volume of water in the volumetric flask shrinks due to the increase in water density. The LBW content of the sample was calculated based on the total volume change in the volumetric flask containing the soil and water.

The test mechanism of the volumetric flask method is shown in Figure 2. Two graduated volumetric flasks of $255 \mathrm{~mL}$ capacity were used; their accuracy was within $0.05 \mathrm{~mL}$. To eliminate the influence of water evaporation, one flask was used to measure the evaporation loss, while the other was used to measure the change in the total volume of soil and water. The flasks were cleaned with deaired water using an ultrasonic cleaner, and then they were oven-dried at $105^{\circ} \mathrm{C}$ for 12 hours. At $25^{\circ} \mathrm{C}$ temperature, the density of distilled water was $0.997 \mathrm{~g} / \mathrm{cm}^{3}$. To accurately measure $254 \mathrm{~mL}$ distilled water, $253.24 \mathrm{~g}$ distilled water was put into one of the volumetric flasks, and the water level was recorded. This flask was used to measure the evaporation loss. The soil sample was dried at $105^{\circ} \mathrm{C}$ for 8 hours [14]. $20 \mathrm{~g}$ dried soil sample was put into a dry flask, and a particular volume of distilled water was slowly poured into it. The flask was shaken to remove trapped air bubbles. To maintain a constant temperature, both volumetric flasks were placed in a $25^{\circ} \mathrm{C}$ temperature water bath. The room temperature was maintained at about $25^{\circ} \mathrm{C}$ to avoid any environmental influence. For both flasks, the liquid level was recorded every 24 hours. When the change in the liquid level of both flasks was the same, the test was terminated. The above procedure was followed for all of the soil samples. Before testing the LBW content, the LBW content of commercial standard sand was tested by this method. Test results showed that the measured LBW content of standard sand was almost zero, which is consistent with the finding (less than $0.37 \%$ ) reported by Wang et al. [14]. This implies that the LBW content can be measured by the volumetric flask method.

3.4. Consolidation Tests on Saturated Soils. This section aims to understand the effect of LBW on the consolidation behavior of saturated soils. One-dimensional consolidation tests were 


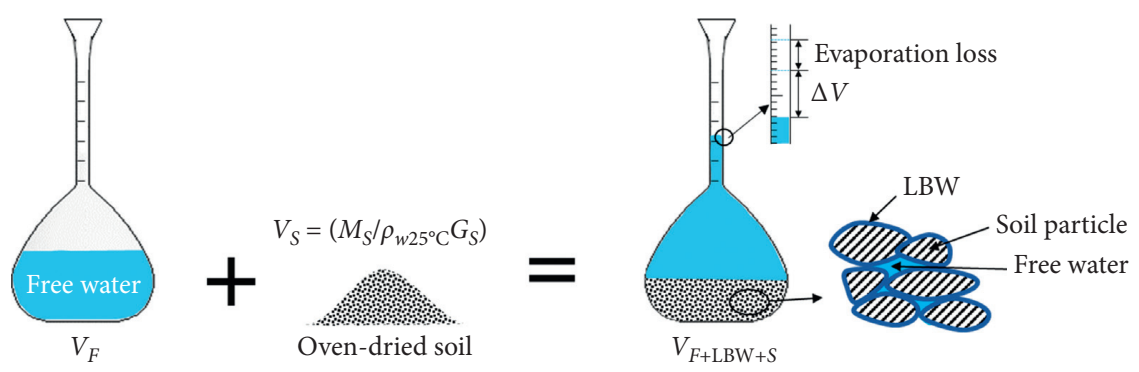

FIgURE 2: Procedure for measuring the LBW content. Note: $\Delta V$ is the reduction in volume of free water converted to loosely bound water; LBW is the loosely bound water.

conducted based on Terzaghi's consolidation theory. Because the maximum dry density and the optimum water content of the $\mathrm{MH}$ soil were about $1.61 \mathrm{~g} / \mathrm{cm}^{3}$ and $23.0 \%$, respectively, an initial void ratio of 0.81 that corresponded to the void ratio at 93\% compactness was considered for this type of soil during specimen preparation. To eliminate the influence of void ratio, the initial void ratio of 0.81 was also taken for the other four soils. Consolidation tests were conducted with a consolidation ring of $20 \mathrm{~mm}$ in height and $61.8 \mathrm{~mm}$ in diameter as per ASTM D2435-11. According to the overburden pressure in the actual embankment, a maximum pressure of $400 \mathrm{kPa}$ was considered. Loading was applied in a consecutive order of $50 \mathrm{kPa}$, $100 \mathrm{kPa}, 200 \mathrm{kPa}, 300 \mathrm{kPa}$, and $400 \mathrm{kPa}$. After completion of the tests, the soil specimens were put in an oven to determine the water contents.

Consolidation tests were also conducted on saturated soil samples prepared at an identical modified void ratio $\left(e^{\prime}\right)$. Note that the tests could not be conducted at 93\% compactness of the $\mathrm{MH}$ soil because the difference in the LBW contents of different soils would make the dry densities of other soils, especially the SC soil with the lowest LBW content, too high to be compacted easily, resulting in a waste of materials and increased labor for compaction. Therefore, a modified void ratio of 0.33 was used to ensure that the dry density of the tested soil sample was within the compactness commonly used in engineering practice.

3.5. Permeability Tests on Saturated Soils. Permeability tests were carried out to evaluate the effect of LBW on the permeability coefficient in accordance with ASTM D5084. The soil specimens of $\mathrm{CH}, \mathrm{MH}, \mathrm{CL}, \mathrm{ML}$, and SC were prepared, considering the same initial void ratio of 0.81 . The specimens of four fine-grained soils (i.e., $\mathrm{CH}, \mathrm{MH}, \mathrm{CL}$, and $\mathrm{ML}$ ) were tested with a falling-head permeability test device; the coarse-grained soil (i.e., SC) was tested with a constant-head permeability test apparatus. After considering the LBW content, the initial void ratio was modified to 0.33 for all soil specimens. The same permeability tests were performed on the new soil specimens that were $40 \mathrm{~mm}$ in height and $61.8 \mathrm{~mm}$ in diameter. After static compaction, the samples were saturated in vacuum for 24 hours, and then they were used for permeability tests.

3.6. Consolidation Tests on Unsaturated Soils. To investigate the effect of LBW on the compressibility of unsaturated soil samples, consolidation tests were conducted on the MH soil.
Different dry densities (i.e., $1.46 \mathrm{~g} / \mathrm{cm}^{3}, \quad 1.40 \mathrm{~g} / \mathrm{cm}^{3}$, $1.38 \mathrm{~g} / \mathrm{cm}^{3}$, and $\left.1.33 \mathrm{~g} / \mathrm{cm}^{3}\right)$ and water contents $(27 \%, 29.4 \%$, $32 \%$, and $34 \%$ ) were considered during specimen preparations, and all water contents were on the wet side of the optimum water content. After the soil specimens were prepared, they were sealed and stored in a desiccator for 24 hours. The test apparatus and the loading process were the same as those for the saturated consolidation test, and the tests were conducted as per ASTM D2435-11. To reduce the loss of water due to evaporation, the consolidometer was covered with a wet cloth during each test.

\section{Results and Discussion}

4.1. Verification of the $L B W$ Density. The LBW density was previously assumed to be $1.3 \mathrm{~g} / \mathrm{cm}^{3}$ based on the findings reported in the literature. To verify the rationality of the assumption, consolidation tests were conducted on saturated $\mathrm{MH}$ and $\mathrm{SC}$ soil specimens with the same initial modified void ratio (i.e., 0.33). Three LBW densities of $1.2 \mathrm{~g} / \mathrm{cm}^{3}, 1.3 \mathrm{~g} / \mathrm{cm}^{3}$, and $1.4 \mathrm{~g} / \mathrm{cm}^{3}$ were considered when calculating the modified void ratio. The compression of the specimens with time is illustrated in Figure 3. It is observed that when the LBW density was assumed to be $1.2 \mathrm{~g} / \mathrm{cm}^{3}$ or $1.4 \mathrm{~g} / \mathrm{cm}^{3}$, the compression curves obviously vary between different soils. By contrast, when an LBW density of $1.3 \mathrm{~g} / \mathrm{cm}^{3}$ was considered, the compression curves of different soils approximate. This indicates that it is reasonable to assume the LBW density to be $1.3 \mathrm{~g} / \mathrm{cm}^{3}$.

Therefore, equation (5) can be rewritten as

$$
e^{\prime}=\frac{e+1}{1+\left(\rho_{s} / 1.3\right) w_{g}}-1 \text {. }
$$

4.2. Mineral Compositions of Different Soils. The XRD results in Figures 4 and 5 show that the five soil samples all contained a large amount of quartz and minor montmorillonite; however, their illite and kaolinite contents were quite different. And the mineral compositions of all soil samples are summarized in Table 2.

Montmorillonite, illite, and kaolinite are clay minerals that have a high affinity for water due to their small particle size and high surface activity. This affinity for water can be attributed to hydrogen bonding (oxygen or hydroxyl molecules attract the hydrogen of water), van der Waals attractions, and charged 


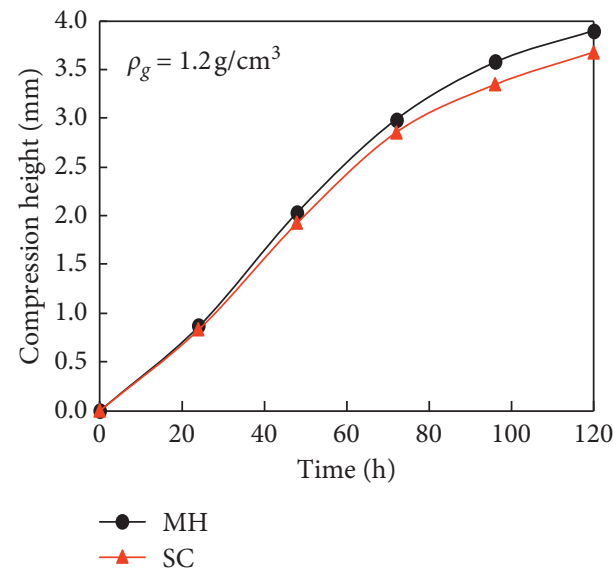

(a)

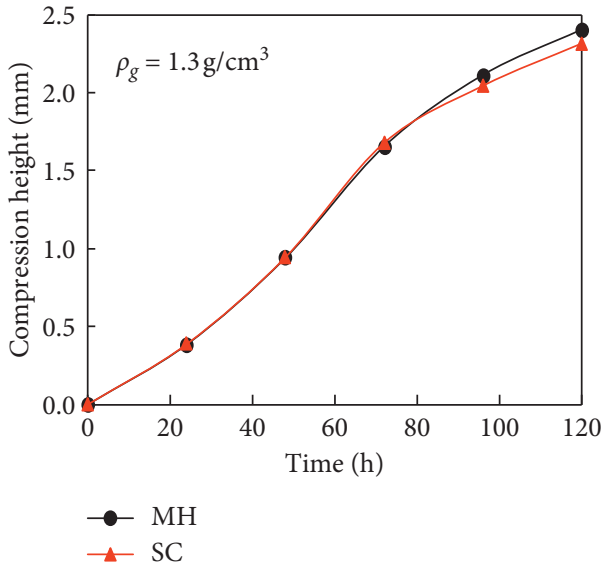

(b)

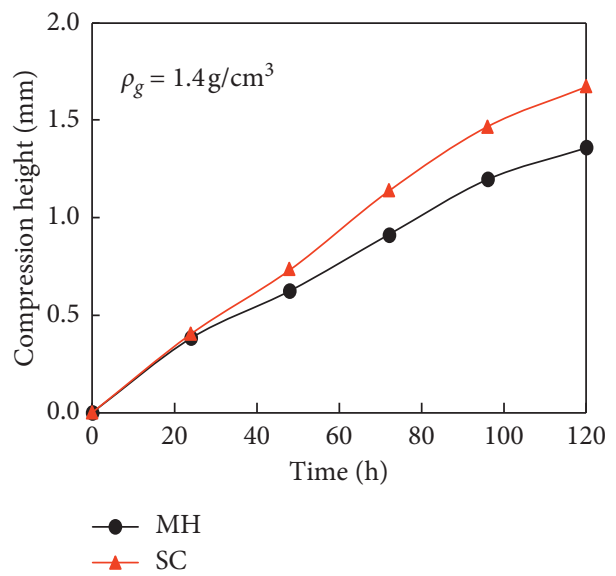

(c)

Figure 3: Compression curves of $\mathrm{MH}$ and SC considering different LBW densities. (a) $\rho_{g}=1.2 \mathrm{~g} / \mathrm{cm}^{3}$. $(\mathrm{b}) \rho_{g}=1.3 \mathrm{~g} / \mathrm{cm}^{3}$. (c) $\rho_{g}=1.4 \mathrm{~g} / \mathrm{cm}^{3}$.

surface-dipole attractions [35]. Among these different types of bonding, hydrogen bonding is the strongest and is considered to be the primary reason for the swelling of expansive soils after water absorption [36]. In the clay-water system, some water molecular layers, designated as LBW, surround clay particles and are tightly held by clay particle surfaces [37]. In this study, the clay mineral content of $\mathrm{CH}$ was higher than those of the other soils; hence, the $\mathrm{CH}$ soil had the highest water-holding capacity.

4.3. LBW Contents of Different Soils. The LBW content was calculated by the following equation:

$$
w_{g}=\frac{\rho_{g} \rho_{w t}}{\rho_{g}-\rho_{w t}} \cdot \frac{\Delta V}{m_{s}},
$$

where $\rho_{w t}$ is the bulk density of free water at $25^{\circ} \mathrm{C}$ and $\Delta V$ is the change in total volume when the water is converted from free water to LBW and can be calculated by

$$
\Delta V=\frac{m_{s}}{\rho_{s}}-V_{t}
$$

where $V_{t}$ is the change in water volume in the volumetric flask.
Table 3 shows that the LBW contents of the five soil samples were different. It is observed that the LBW content increased with the increasing clay content. This is because clay particles have large surface energy and strong bonding capacity to form bound water. Moreover, the LBW content $\left(w_{g}\right)$ was slightly smaller than the plastic limit $\left(w_{p}\right)$. A previous study [38] also stated that there was a linear correlation between the LBW content and the plastic limit of soil. Thus, the following equation was derived by fitting the experimental data reported in the literature as well as those obtained in this study (see Figure 6):

$$
w_{g}=0.8493 w_{p}
$$

The coefficient of determination of equation (9) is $R^{2}=0.9897$. The determination of the LBW content is timeconsuming by laboratory tests; thus, equation (9) can be used for this purpose.

4.4. Compressibility of Saturated Soils. The relationship between the void ratio $e$ and the overburden pressure $p$ can effectively predict the settlement of the soil [26]. The $e-\log p$ curves are presented in Figures 7 and 8 . It is observed that the void ratio of all five soils decreased with increasing 

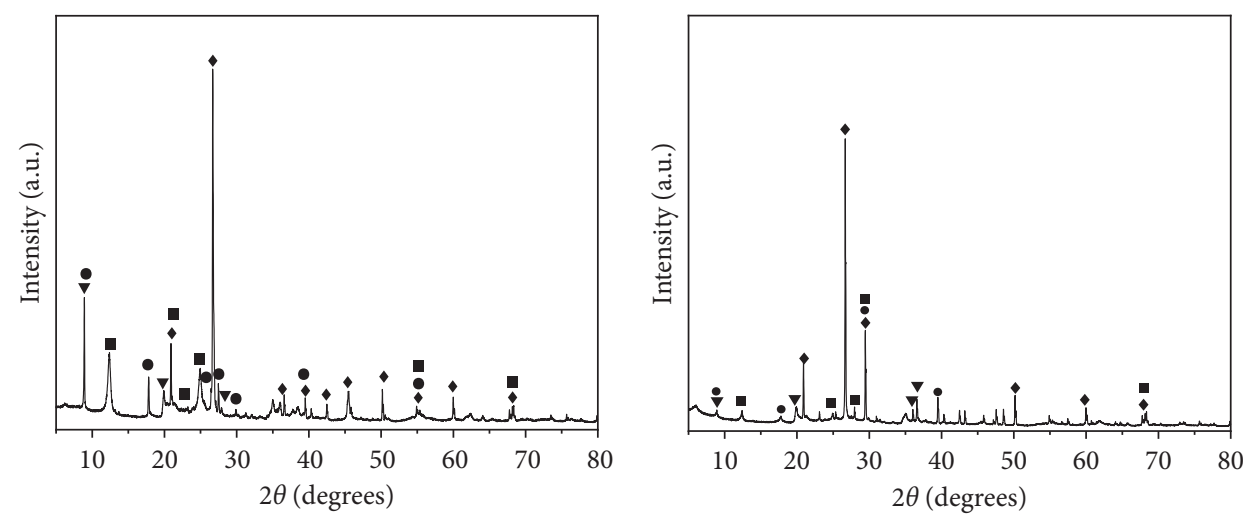

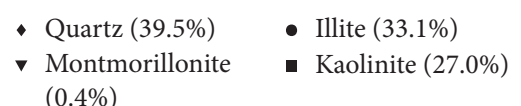

(a)

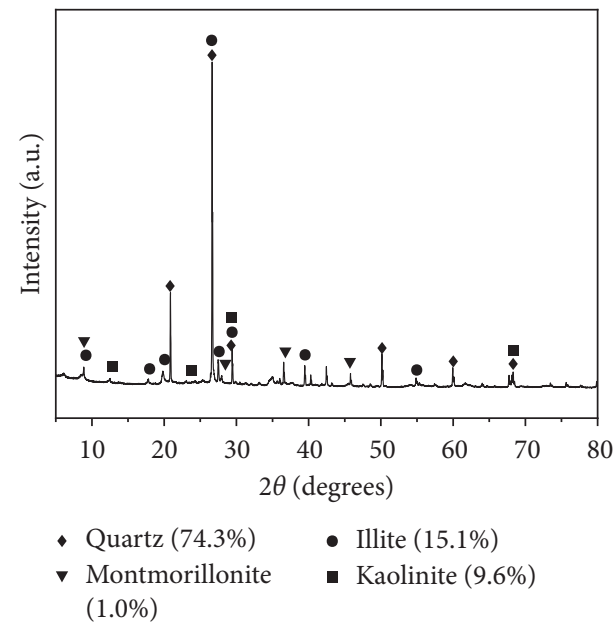

(c)
- Quartz (69.1\%)
- Illite (11.5\%)
v Montmorillonite
- Kaolinite (18.2\%)
$(1.2 \%)$

(b)

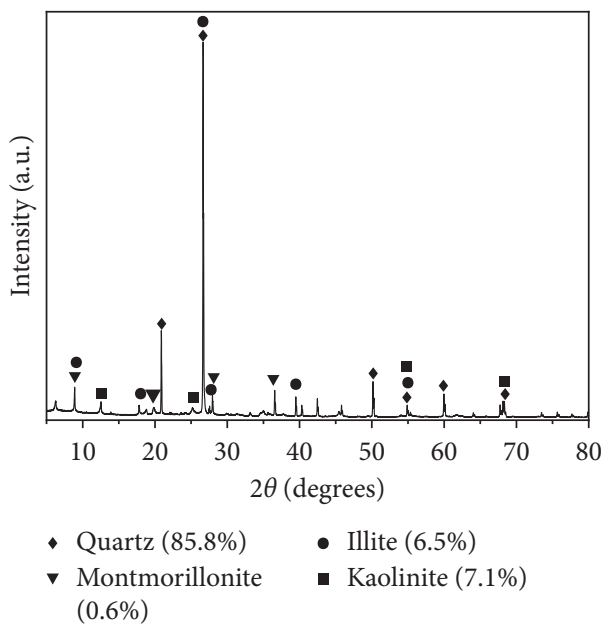

(d)

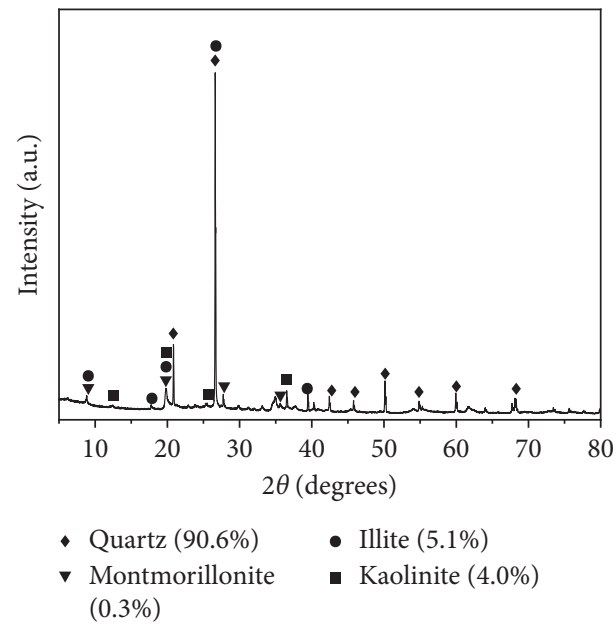

(e)

Figure 4: X-ray diffraction patterns for different soil specimens. (a) CH soil. (b) MH soil. (c) CL soil. (d) ML soil. (e) SC soil.

consolidation pressure, which can be explained by Terzaghi's consolidation theory. As the consolidation pressure varied from $50 \mathrm{kPa}$ to $400 \mathrm{kPa}$, the SC soil had the largest change in the void ratio and the $\mathrm{CH}$ soil showed the lowest change although they were prepared at the same initial conventional void ratio. Table 3 shows that the LBW content was the highest for the $\mathrm{CH}$ soil, whereas it was the lowest for the SC soil. Therefore, the change in the void ratio can be explained 


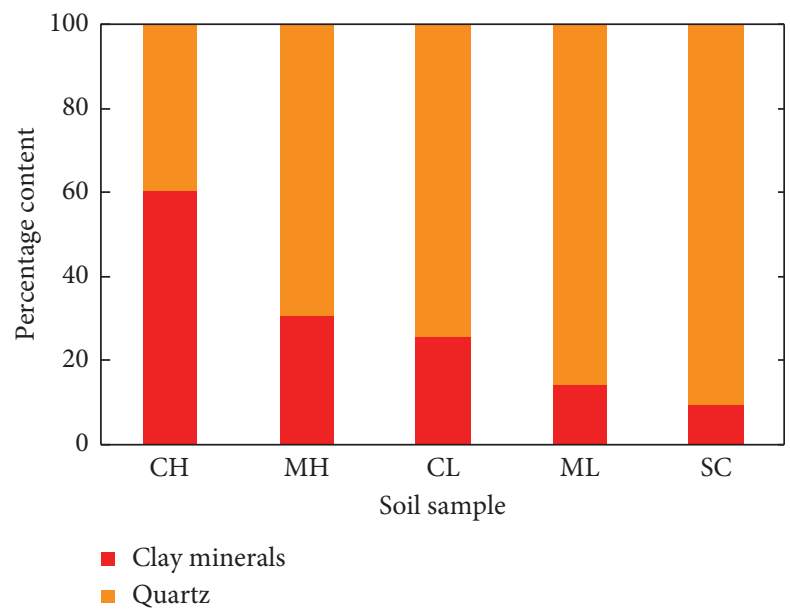

Figure 5: Contents of quartz and clay minerals in different soils.

TABle 2: Mineral compositions of different soil samples.

\begin{tabular}{lcccc}
\hline Sample & \multicolumn{2}{c}{ Mineral composition (\%) } & Illite & Kaolinite \\
\hline CH & Quartz & Montmorillonite & 33.1 & 27.0 \\
MH & 39.5 & 0.4 & 11.5 & 18.2 \\
CL & 69.1 & 1.2 & 15.1 & 9.6 \\
ML & 74.3 & 1.0 & 6.5 & 7.1 \\
SC & 85.8 & 0.6 & 5.1 & 4.0 \\
\hline
\end{tabular}

TABLE 3: Parallel LBW content tests on different soil samples.

\begin{tabular}{|c|c|c|c|c|c|c|c|c|c|c|}
\hline Sample & $\begin{array}{c}\text { Dry } \\
\text { soil } \\
\text { mass } \\
(\mathrm{g})\end{array}$ & $\begin{array}{l}\text { Specific } \\
\text { gravity }\end{array}$ & $\begin{array}{l}\text { Dry soil } \\
\text { volume } \\
\left(\mathrm{cm}^{3}\right)\end{array}$ & $\begin{array}{l}\text { Distilled } \\
\text { water } \\
\text { volume } \\
(\mathrm{mL})\end{array}$ & $\begin{array}{l}\text { Final } \\
\text { reading } \\
(\mathrm{mL})\end{array}$ & $\begin{array}{c}\text { Solution } \\
\text { volume } \\
\text { increment } \\
(\mathrm{mL})\end{array}$ & $\begin{array}{l}\text { Evaporation } \\
(\mathrm{mL})\end{array}$ & $\begin{array}{c}\text { Solution } \\
\text { shrinking } \\
\text { volume }(\mathrm{mL})\end{array}$ & $\begin{array}{c}\text { LBW } \\
\text { content } \\
(\%)\end{array}$ & $\begin{array}{c}\text { Average } \\
\text { value (\%) }\end{array}$ \\
\hline $\mathrm{CH}-1$ & 27.10 & \multirow[t]{2}{*}{2.71} & 10.00 & 243.00 & 250.92 & 7.92 & 0.20 & 2.09 & 30.06 & \multirow{2}{*}{30.14} \\
\hline $\mathrm{CH}-2$ & 27.10 & & 10.00 & 243.00 & 250.91 & 7.91 & 0.20 & 2.09 & 30.22 & \\
\hline MH-1 & 27.30 & \multirow[t]{2}{*}{2.73} & 10.00 & 243.00 & 250.95 & 7.95 & 0.20 & 2.05 & 29.36 & \multirow{2}{*}{29.44} \\
\hline MH-2 & 27.30 & & 10.00 & 243.00 & 250.94 & 7.94 & 0.20 & 2.04 & 29.52 & \\
\hline CL-1 & 26.60 & \multirow[t]{2}{*}{2.66} & 10.00 & 243.00 & 251.56 & 8.56 & 0.20 & 1.44 & 20.04 & \multirow{2}{*}{20.12} \\
\hline CL-2 & 26.60 & & 10.00 & 243.00 & 251.57 & 8.57 & 0.20 & 1.43 & 20.20 & \\
\hline ML-1 & 27.50 & \multirow[t]{2}{*}{2.75} & 10.00 & 243.00 & 251.77 & 8.77 & 0.20 & 1.23 & 16.23 & \multirow{2}{*}{16.31} \\
\hline ML-2 & 27.50 & & 10.00 & 243.00 & 251.76 & 8.76 & 0.20 & 1.24 & 16.39 & \\
\hline SC-1 & 26.90 & \multirow[t]{2}{*}{2.69} & 10.00 & 243.00 & 251.97 & 8.97 & 0.20 & 1.03 & 13.37 & \multirow{2}{*}{13.21} \\
\hline SC-2 & 26.90 & & 10.00 & 243.00 & 251.99 & 8.99 & 0.20 & 1.01 & 13.05 & \\
\hline
\end{tabular}

in terms of LBW contents. In the present range of consolidation pressure, free water was removed easily, but LBW could not be removed due to the bonding force between the water and soil particles, which is consistent with the findings reported by Shang et al. [25] and Li et al. [39]. At a given water content, the higher the LBW content, the lower the free water content, and the smaller the change of the void ratio during consolidation. Hence, it can be concluded that a reduction in the void ratio is related to the LBW content. Moreover, the LBW content increased, while the change in the void ratio decreased with the increase in the clay content. The initial water content was higher than the corresponding LBW content for all of the soil specimens. At a given water content, when the LBW content is higher, the content of free water is smaller, so there is less expulsion of water in consolidation. Therefore, the change in the void ratio is less for soils (e.g., $\mathrm{CH}$ ) with a high LBW content. The $C_{c}$ values of the soil specimens are shown in Table 4 . It is noted that, for soils with a greater LBW content, the $C_{c}$ value is smaller, revealing that the compressibility of soil is affected by the LBW content. When LBW was considered a part of the solid phase, the trend for all of the soil specimens was almost the same, as can be seen in Figure 8 . The change in the void ratio with consolidation pressure was nearly the same regardless of soil types. Hence, it is reasonable to assume LBW to be a part of the solid phase. 


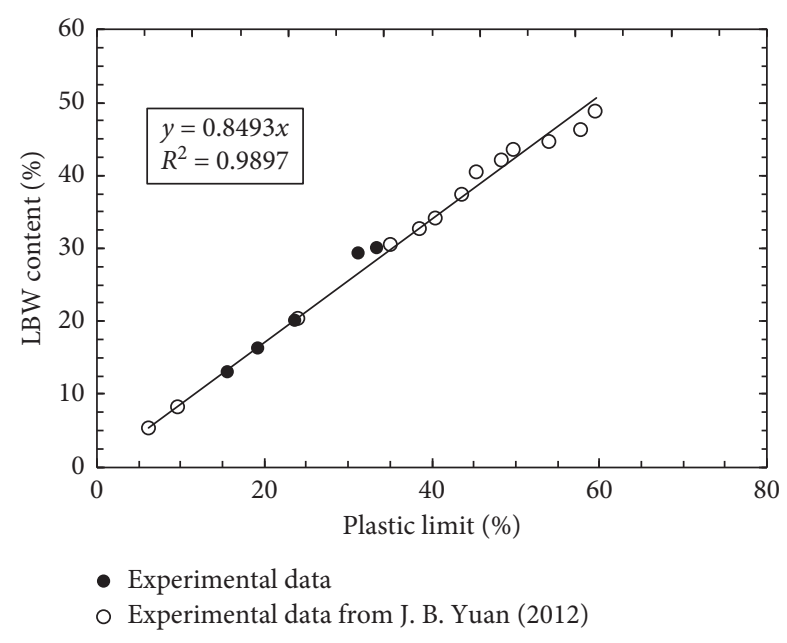

FIGURE 6: Fitting curve of the relationship between the LBW content and the plastic limit.

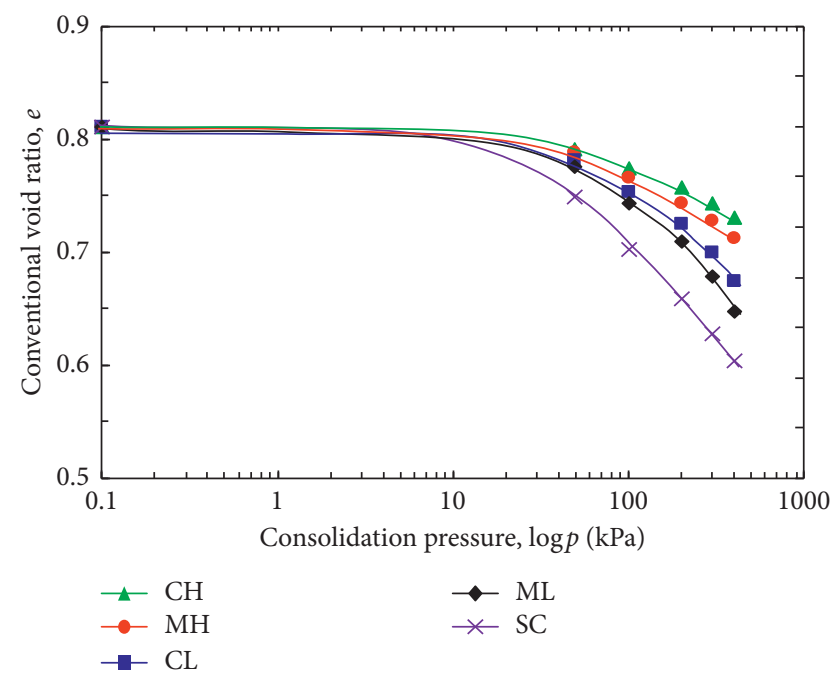

Figure 7: Compressive behavior of saturated soils with the same initial conventional void ratio.

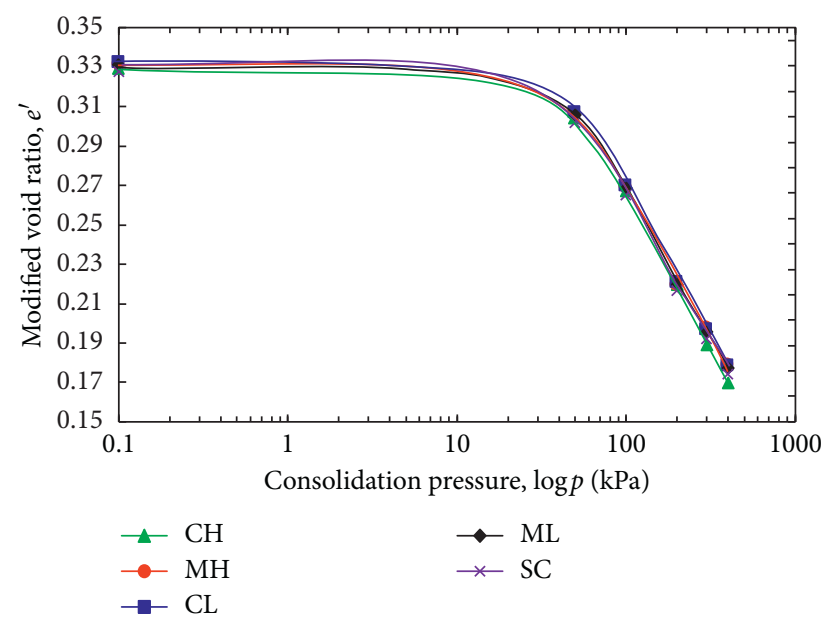

FIGURE 8: Compressive behavior of saturated soils with the same initial modified void ratio.
TABle 4: Compression indexes of different soil samples.

\begin{tabular}{lccccc}
\hline Sample & $\mathrm{CH}$ & $\mathrm{MH}$ & $\mathrm{CL}$ & $\mathrm{ML}$ & $\mathrm{SC}$ \\
\hline$C_{c}$ & 0.067 & 0.083 & 0.118 & 0.142 & 0.161 \\
\hline
\end{tabular}

4.5. Permeability Coefficients of Saturated Soils. The permeability coefficients $(k)$ of saturated soil specimens are presented in Table 5. It is noted that the $k$ values of these soil specimens were different. At the same initial conventional void ratio, the soil (i.e., $\mathrm{CH}$ ) with the largest $\mathrm{LBW}$ content had the least $k$ value in comparison with other soils. Because free water cannot pass through LBW, the effective void for flowing water is reduced as the LBW content increases. Actually, the space occupied by LBW can be regarded as an ineffective void, as explained by Zhang et al. [40]. As a result, the presence of LBW in soil reduces its $k$ value. However, the $k$ values of soil specimens prepared at the identical initial modified void ratio were approximately the same. In other words, the $k$ values were almost equal for all soil specimens when LBW was considered a part of the solid phase.

4.6. Compressibility of Unsaturated Soils. Table 6 presents the degrees of saturation of the unsaturated $\mathrm{MH}$ soil before and after consolidation tests. It shows that the degree of saturation calculated from the conventional void ratio reached above $100 \%$. This was inconsistent with the actual situation caused by the density problem of the water in soil, as mentioned by Villar [41]. Therefore, the degree of saturation was recalculated based on the modified void ratio taking the density of LBW into account. The results indicate that the recalculated degree of saturation was in accordance with common sense (Table 6). Figure 9 illustrates the compressive behavior of the $\mathrm{MH}$ soil with different initial dry densities and initial water contents. It shows that the void ratio of soil specimens with the same dry density varied with the change in the water content. At the same water content, the larger the dry density of soil, the smaller the change of the void ratio. This is because a higher dry density leads to a higher content of soil particles per volume, and consequently, the soil has a stronger adsorption capacity to bound water. The discharge of pore gas constitutes the main part of the compression process.

The change in the conventional compression index of the unsaturated MH soil is shown in Figure 10. Since the initial water content of the soil specimens was smaller than the liquid limit, the conventional compression index decreased with the increase in the initial water content. When the water content was lower than the LBW content, the water-adsorption film of the soil particles thickened as the water content increased. Therefore, the solid volume of the soil increased, and the volume ratio of air became smaller. Because of the relatively strong viscosity of LBW, it was difficult to discharge LBW at a consolidation pressure of $1.6 \mathrm{MPa}$ [39]; this led to a decrease in the compression index. The water content was less than the liquid limit although it had a value higher than the LBW content. With the increase of the water content, the effect of the DDL made LBW bind to the surfaces of soil particles at certain viscosity and fluidity. Hence, the volume ratio of air became smaller. At a consolidation pressure of $200 \mathrm{kPa}$, LBW 
TABLE 5: Permeability coefficients of soil samples with the same $e_{0}$ or $e_{0}^{\prime}$.

\begin{tabular}{|c|c|c|c|c|}
\hline Sample & $e_{0}$ & $k(\mathrm{~cm} / \mathrm{s})$ & $e_{0}^{\prime}$ & $k(\mathrm{~cm} / \mathrm{s})$ \\
\hline$\overline{\mathrm{CH}}$ & & $1.53 \times 10^{-6}$ & & $7.57 \times 10^{-5}$ \\
\hline $\mathrm{MH}$ & & $4.47 \times 10^{-6}$ & & $6.50 \times 10^{-5}$ \\
\hline $\mathrm{CL}$ & 0.81 & $6.61 \times 10^{-5}$ & 0.33 & $8.01 \times 10^{-5}$ \\
\hline ML & & $6.95 \times 10^{-5}$ & & $4.71 \times 10^{-5}$ \\
\hline SC & & $1.15 \times 10^{-4}$ & & $8.21 \times 10^{-5}$ \\
\hline
\end{tabular}

Note: $e_{0}$ is the initial conventional void ratio; $e_{0}^{\prime}$ is the initial modified void ratio; $k$ is the permeability coefficient.

TABLE 6: Degree of saturation of the $\mathrm{MH}$ soil before and after the consolidation test.

\begin{tabular}{|c|c|c|c|c|c|}
\hline \multirow[t]{2}{*}{ Water content (\%) } & \multirow[t]{2}{*}{ Dry density $\left(\mathrm{g} \cdot \mathrm{cm}^{-3}\right)$} & \multicolumn{2}{|c|}{$\begin{array}{l}\text { Degree of saturation calculated by the } \\
\text { conventional void ratio }(e)\end{array}$} & \multicolumn{2}{|c|}{$\begin{array}{l}\text { Degree of saturation calculated by the } \\
\text { modified void ratio }\left(e^{\prime}\right)\end{array}$} \\
\hline & & Initial value (\%) & Final value (\%) & Initial value (\%) & Final value (\%) \\
\hline \multirow{4}{*}{34.0} & 1.46 & 107.08 & 115.72 & 85.75 & 93.64 \\
\hline & 1.41 & 99.53 & 112.48 & 79.67 & 90.04 \\
\hline & 1.38 & 95.26 & 109.04 & 76.25 & 87.28 \\
\hline & 1.33 & 88.72 & 102.05 & 71.70 & 82.97 \\
\hline \multirow{4}{*}{32.0} & 1.46 & 100.90 & 111.13 & 79.51 & 87.57 \\
\hline & 1.41 & 93.68 & 104.84 & 73.81 & 82.62 \\
\hline & 1.38 & 89.65 & 99.58 & 66.12 & 73.98 \\
\hline & 1.33 & 83.91 & 93.88 & 17.18 & 11.80 \\
\hline \multirow{4}{*}{29.4} & 1.46 & 92.59 & 103.31 & 71.23 & 78.81 \\
\hline & 1.41 & 86.06 & 96.33 & 66.20 & 74.10 \\
\hline & 1.38 & 82.37 & 93.28 & 63.36 & 71.76 \\
\hline & 1.33 & 77.46 & 89.16 & 59.58 & 68.90 \\
\hline \multirow{4}{*}{27.0} & 1.46 & 85.13 & 96.42 & 65.49 & 74.17 \\
\hline & 1.41 & 79.04 & 89.20 & 60.80 & 68.61 \\
\hline & 1.38 & 75.46 & 86.60 & 58.19 & 66.62 \\
\hline & 1.33 & 70.80 & 81.56 & 54.46 & 62.74 \\
\hline
\end{tabular}

can migrate to adjacent soil particles; however, it remains difficult to discharge. The water contents of soil specimens exhibited different decreases compared to the initial values. At an initial dry density of $1.46 \mathrm{~g} / \mathrm{cm}^{3}$ and an initial water content of $34.0 \%$, the water content of the MH soil decreased the most, to reach a value of $32.74 \%$. This was larger than the LBW content of the $\mathrm{MH}$ soil. Therefore, for unsaturated soil specimens, when the initial water content was lower than the LBW content, the soil compression was mainly due to the discharge of pore air, and the water content was almost unchanged after the experiment. When the initial water content is higher than the LBW content, the soil compression process involved the discharge of pore air, free water, and the outermost water film on particle surfaces. After the test, the water content was not lower than the LBW content, and LBW could be considered a part of the solid phase.

Through the consolidation and permeability tests of five soil samples, the LBW content was found to have a significant influence on the consolidation and compression of the soil. In previous specifications, when calculating the compression index of soil, all water in the soil was regarded as free water. However, according to the results of LBW content tests and consolidation tests, normative calculations do not precisely match the engineering reality. In engineering practice, the temperature of embankment fillers is rarely higher than $25^{\circ} \mathrm{C}$; even in hot and humid areas, the temperature does not exceed $30^{\circ} \mathrm{C}$. Thus, the change in $\mathrm{LBW}$ content is not more than $1 \%$ [42]. In addition, an on-site investigation showed that the water content of a fine-grained soil embankment increased yearly from an initial value to an equilibrium one approaching the plastic limit in southern China [43]. When the water content of soil reaches the plastic limit, a full layer of LBW is formed [34]. In the operation period, the LBW content of the fine-grained soil is relatively stable in the service life of the embankment after the water content reaches its equilibrium. LBW can thus be regarded as a part of the solid phase of fine-grained soil.

\section{Modified Compression Index and Its Application}

The existence of LBW affects the pore characteristics and consolidation behavior of fine-grained soils, as deduced from the above-described consolidation and permeability tests. To accurately predict the consolidation settlement of soil, consolidation characteristics need to be predicted correctly. In the present study, the compression index was modified on the basis of the modified void ratio, and it was used to predict the settlement of a road embankment.

5.1. Compression Index considering $L B W$. The modified void ratio can be obtained by substituting equation (9) into (6):

$$
e^{\prime}=\frac{e+1}{1+\left(\rho_{s} / 1.3\right) \times 0.8493 w_{p}}-1 .
$$




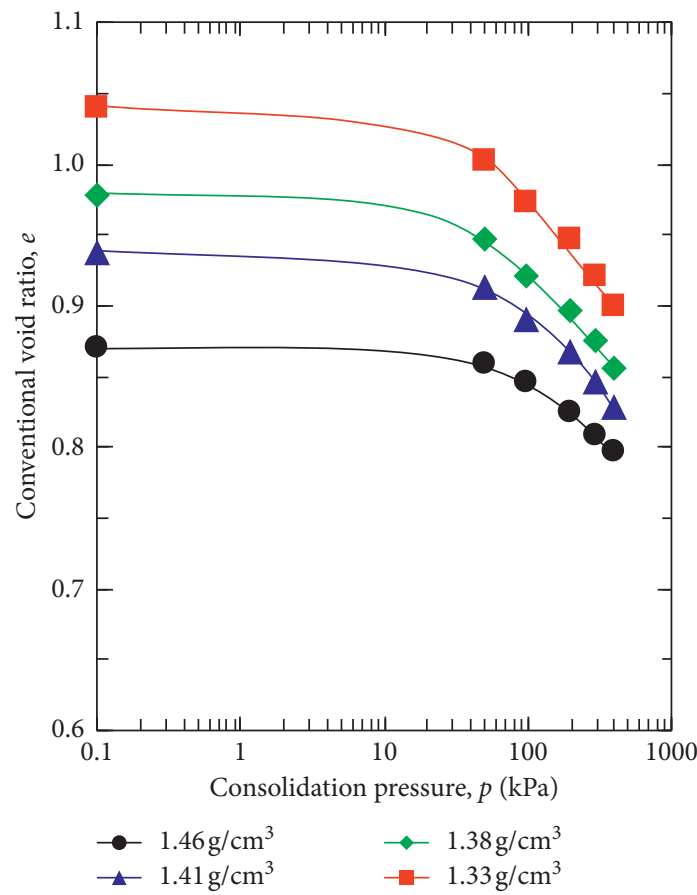

(a)

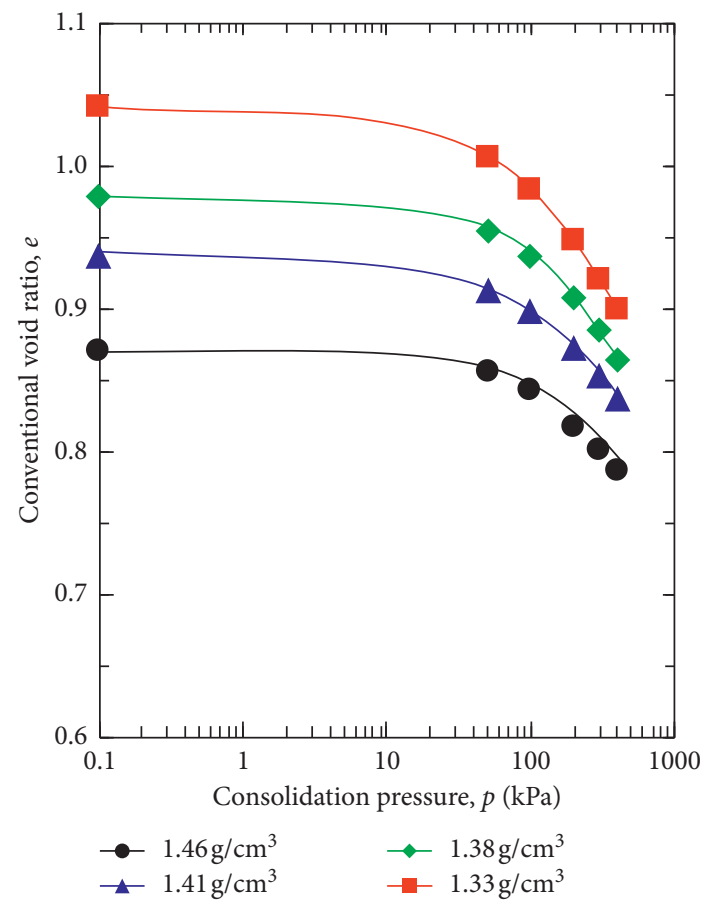

(c)

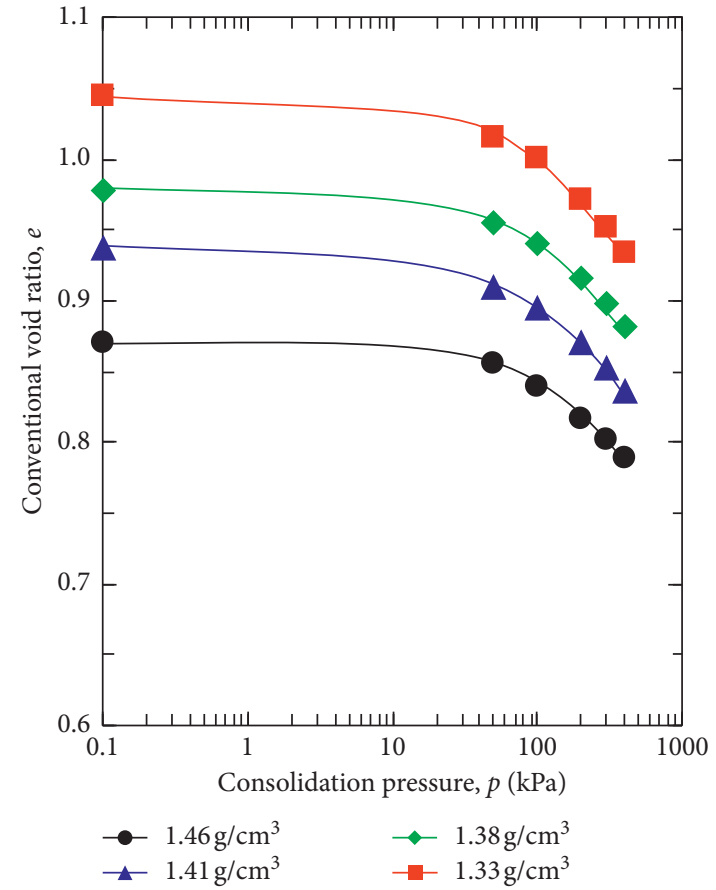

(b)

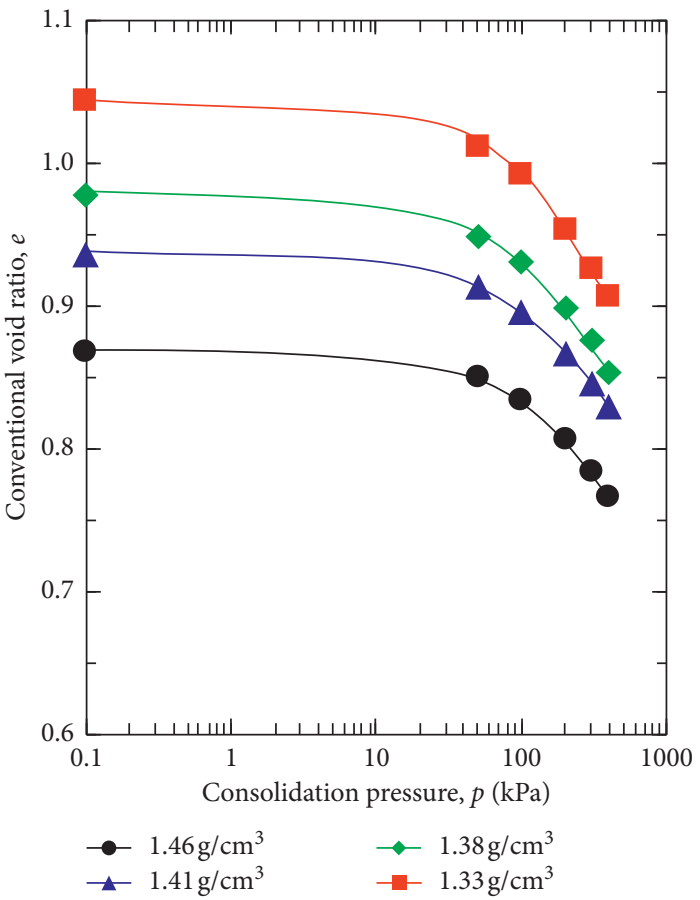

(d)

Figure 9: Compressive behavior of the unsaturated $\mathrm{MH}$ soil with different water contents and dry densities. (a) Water content $34.0 \%$. (b) Water content $32.0 \%$. (c) Water content $29.4 \%$. (d) Water content $27.0 \%$.

The compression index is an important characteristic of soil compression, and it can be calculated by the following equation according to Terzaghi's consolidation theory:

$$
C_{c}=\frac{\Delta e}{\Delta \lg p},
$$

where $p$ is the consolidation pressure.

Based on the modified void ratio, a modified compression index is obtained:

$$
C_{c}^{\prime}=\frac{\Delta e^{\prime}}{\Delta \lg p}
$$




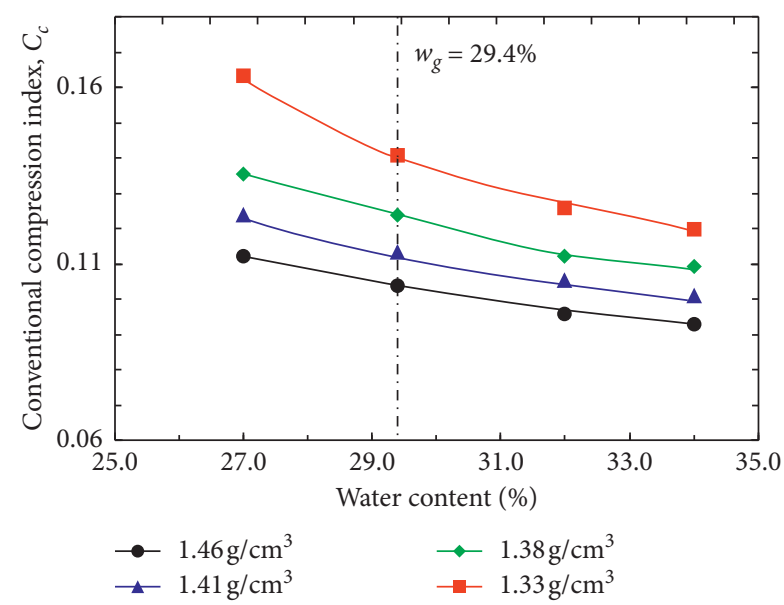

FIgURE 10: Conventional compression indexes of the unsaturated $\mathrm{MH}$ soil with different dry densities.

where $C_{c}^{\prime}$ is the modified compression index.

Combining equations (10)-(12), one can deduce the following equation:

$$
C_{c}^{\prime}=\frac{\Delta e^{\prime}}{\Delta \lg p}=\frac{C_{c}}{1+\left(G_{s} / 1.3\right) \times 0.8493 w_{p}} .
$$

Sridharan and Jayadeva [10] proposed a theoretical equation for the compression index from the microscopic point of view, and the equation is expressed as

$$
C_{c t}=\frac{G_{s} \gamma_{w} S \times 10^{-6}}{0.4367 \sqrt{(n / \varepsilon T) v}}
$$

where $C_{c t}$ is the theoretical compression index; $\gamma_{w}$ is the unit weight of water; $S$ is the specific surface area of soil particles; $n$ is the concentration of the pore liquid ions; $\varepsilon$ is the dielectric constant $(78.54 \mathrm{~F} / \mathrm{m}) ; v$ is the valency of the cation; and $T$ is Kelvin's constant $(298 \mathrm{~K})$.

Since equation (14) has a theoretical basis and considers various factors that affect the compression index, the results can be regarded as a benchmark for the compression index. The conventional compression indexes, modified compression indexes, and theoretical compression indexes of the five saturated soils with an initial void ratio of 0.81 were calculated, and the results are shown in Figure 11. It is observed that conventional compression indexes were obviously higher than theoretical values. By contrast, modified compression indexes were quite close to theoretical compression indexes calculated by the equation proposed by Sridharan and Jayadeva [10]. This indicates that the modified compression index is better than the conventional compression index in characterizing the compressive behavior of fine-grained soils. Compared with the theoretical compression index, the determination of the modified compression index needs only macroscopic parameters and thus does not need to conduct a series of microscopic tests. In other words, the modified compression index is more convenient for practical applications than the theoretical one and also more precise than the conventional one.

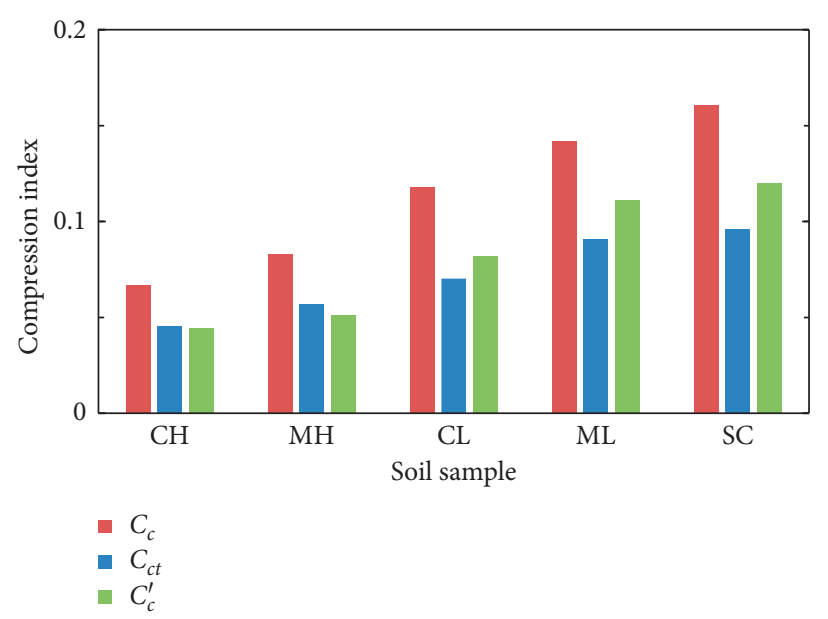

FIgURE 11: Comparison of conventional, theoretical, and modified compression indexes of different soils. Note: $C_{c}$ is the conventional compression index; $C_{c t}$ is the theoretical compression index; $C_{c}^{\prime}$ is the modified compression index.

5.2. Application of the Modified Compression Index. The modified compression index was used to predict the settlement of an embankment section of the Wanning-Yangpu highway in Hainan Province, China. The humid climate in Hainan Province makes it vital to pay special attention to the embankment settlement after constructions. The embankment was $8.0 \mathrm{~m}$ high and $12.25 \mathrm{~m}$ wide. It was filled with a locally available fine-grained soil (i.e., $\mathrm{MH}$ clay), whose physical properties are shown in Table 1. To observe the settlement after construction, two monitoring tubes were set up, with one (S1) located on the bottom of the embankment and the other (S2) located on the top of the embankment. The installation of the upper settlement tube is shown in Figure 12(a). Thus, the difference between the readings of S2 and S1 could be regarded as the settlement of the embankment. Also, the embankment settlement was calculated from the conventional compression index and modified compression index based on the layerwise summation method as recommended by the Chinese standard (JTGD302015):

$$
S_{t}=\sum_{i=1}^{n} \frac{H_{i}}{1+e_{0 i}}\left[C_{c i} \lg \frac{p_{0 i}+\Delta p_{i}}{p_{0 i}}\right]
$$

where $S_{\mathrm{t}}$ is the total settlement; $H_{i}$ is the thickness of the layer $i ; e_{0 i}$ is the initial void ratio of the layer $i ; C_{c i}$ is the compression index of the layer $i ; p_{0 i}$ is the self-weight stress of the layer $i$; and $\Delta p_{i}$ is the additional stress of the layer $i$.

The settlement of the embankment was monitored for 360 days, and the results are shown in Figure 12(b). It is observed that the readings of the monitoring tubes (i.e., S1 and S2) stabilized gradually, and the final settlement of the embankment was approximately $73.3 \mathrm{~mm}$. The total settlements of the embankment calculated using $C_{c}$ and $C_{c}^{\prime}$ were $113.5 \mathrm{~mm}$ and $70.7 \mathrm{~mm}$, respectively. Obviously, the settlement calculated by $C_{c}^{\prime}$ was closer to the measured one, while $C_{c}$ overestimated the settlement. This indicates that the modified compression index can effectively predict the 


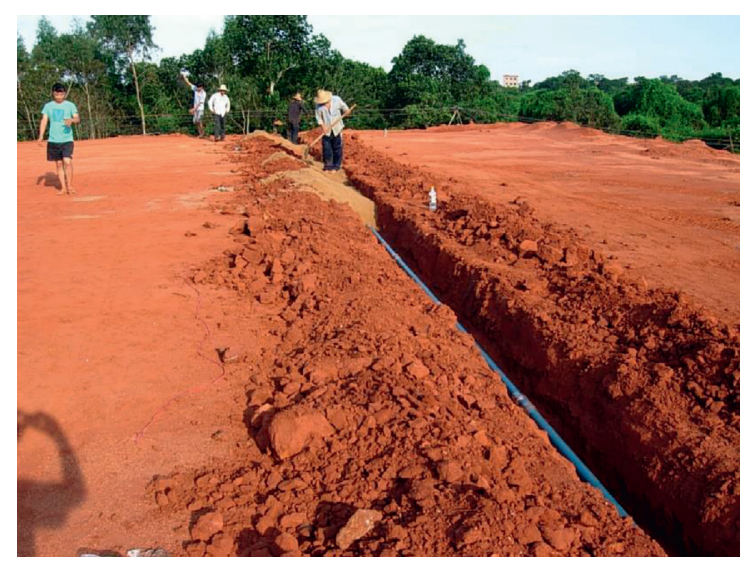

(a)

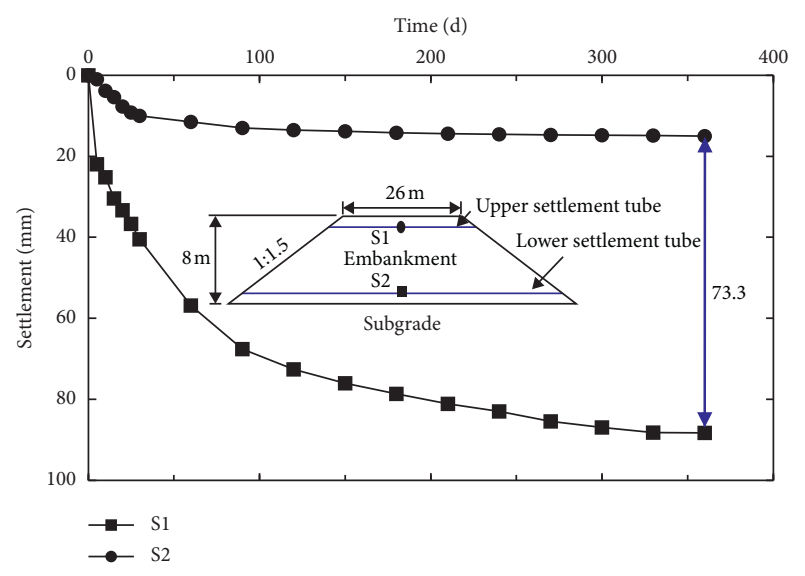

(b)

Figure 12: Field monitoring on the settlement of the Wanning-Yangpu highway embankment. (a) Installation of the upper settlement tube. (b) Monitored settlement.

settlement of fine-grained soil embankments. Therefore, it is reasonable to consider the effect of LBW in evaluating the compressibility of fine-grained soils. It should be mentioned that the prediction of embankment settlements can be greatly improved using the modified compression index, and the prediction results still deviate a lot from the measured data due to the variability of soil properties in the field [44-46]. Thus, the future work could be done by taking the variability and uncertainty of soil parameters into consideration.

\section{Conclusions}

This study investigated the effects of LBW on the compressibility of compacted fine-grained soils. The LBW density of $1.3 \mathrm{~g} / \mathrm{cm}^{3}$ was assumed for the measurement. The modified void ratio was introduced, and LBW was considered a part of the solid phase of soil. The settlement of an embankment was calculated based on the modified compression index and compared with the field data. From the present experimental studies, the following conclusions can be drawn:

(1) It is confirmed that montmorillonite and illite greatly affect the LBW content, and the LBW content varies linearly with the plastic limit. Hence, for engineering convenience, LBW can be estimated from the plastic limit.

(2) For saturated fine-grained soil samples with the same initial void ratio, the compression indexes and permeability coefficients decrease with the increase in the LBW content. When LBW is regarded as a part of the solid phase in soil at the same modified void ratio, the compression indexes and the permeability coefficients of different soils tend to be the same.

(3) For unsaturated soils, the compression of soil during consolidation is due to air discharge when the water content is less than the LBW content, whereas the compression of soil is due to the discharge of both air and water when the water content is higher than the LBW content. This confirms the assumption that LBW is a part of the solid phase.

(4) The modified compression index determined based on the modified void ratio is recommended for calculating the compression of fine-grained soils when the water content is higher than the LBW content.

\section{Data Availability}

The data used to support the findings of this study are included within this article.

\section{Conflicts of Interest}

The authors declare that there are no conflicts of interest regarding the publication of this paper.

\section{Acknowledgments}

This work was supported by the National Natural Science Foundation of China (51978085 and 51108049) and the Highway Industry Standard Compilation Project of Ministry of Transportation (JTG-201507).

\section{References}

[1] U. Dagdeviren, A. S. Demir, and T. F. Kurnaz, "Evaluation of the compressibility parameters of soils using soft computing methods," Soil Mechanics and Foundation Engineering, vol. 55, no. 3, pp. 173-180, 2018.

[2] S. Shimobe and G. Spagnoli, "Some generic trends on the basic engineering properties of fine-grained soils," Environmental Earth Sciences, vol. 78, no. 9, 2019.

[3] R. T. Martin, "Adsorbed water on clay: a review," Clays and Clay Minerals, vol. 9, no. 1, pp. 28-70, 1962.

[4] J. Mitchell and K. Soga, Fundamentals of Soil Behavior, John Wiley \& Sons, Inc. Press, Hoboken, NJ, USA, 2005.

[5] B. P. Radhika, A. Krishnamoorthy, and A. U. Rao, "A review on consolidation theories and its application," International 
Journal of Geotechnical Engineering, vol. 14, no. 1, pp. 9-15, 2020.

[6] L. Q. Sun, J. X. Lu, W. Guo et al., "Models to predict compressibility and permeability of reconstituted clays," Geotechnical Testing Journal, vol. 39, no. 2, pp. 324-330, 2016.

[7] L. L. Zeng, Y. Q. Cai, Y. J. Cui et al., "Hydraulic conductivity of reconstituted clays based on intrinsic compression," Geotechnique, vol. 70, no. 3, pp. 268-275, 2019.

[8] D. R. Petersen, R. E. Link, R. G. Robinson, and M. M. Allam, "Compression index of clays and silts," Journal of Testing and Evaluation, vol. 31, no. 1, pp. 22-27, 2003.

[9] C. Chu, Z. Wu, Y. Deng, Y. Chen, and Q. Wang, "Intrinsic compression behavior of remolded sand-clay mixture," $\mathrm{Ca}$ nadian Geotechnical Journal, vol. 54, no. 7, pp. 926-932, 2017.

[10] A. Sridharan and M. S. Jayadeva, "Double layer theory and compressibility of clays," Géotechnique, vol. 32, no. 2, pp. 133-144, 1982.

[11] J. Chen, A. Anandarajah, and H. Inyang, "Pore fluid properties and compressibility of kaolinite," Journal of Geotechnical and Geoenvironmental Engineering, vol. 126, no. 9, pp. 798-807, 2000.

[12] X. W. Zhang, C. M. Wang, and J. X. Li, "Experimental study of coupling behaviors of consolidation-creep of soft clay and its mechanism," Rock and Soil Mechanics, vol. 32, no. 12, pp. 3584-3590, 2011, in Chinese.

[13] F. C. Wu, "Characteristics of adsorption and binding water of cohesive soil and some characteristics of seepage," Chinese Journal of Geotechnical Engineering, vol. 6, no. 6, pp. 86-95, 1984, in Chinese.

[14] Y. Wang, S. Lu, T. Ren, and B. Li, "Bound water content of airdry soils measured by thermal analysis," Soil Science Society of America Journal, vol. 75, no. 2, pp. 481-487, 2011.

[15] L. Cheng, P. Fenter, K. L. Nagy et al., "Molecular-scale density oscillations in water adjacent to a mica surface," Physical Review Letters, vol. 87, no. 15, p. 156103, 2001.

[16] P. L. Arens, "Moisture content and density of some clay minerals and some remarks on the hydration pattern of clay," Transactions of the International Congress of Soil Science in Transactions of the International Congress of Soil Science, vol. 2, pp. 59-62, 1950.

[17] D. M. Zymnis, A. J. Whittle, and J. T. Germaine, "Measurement of temperature-dependent bound water in clays," Geotechnical Testing Journal, vol. 42, no. 1, pp. 232-244, 2018.

[18] F. Min, C. Peng, and S. Song, "Hydration layers on clay mineral surfaces in aqueous solutions: a Review," Archives of Mining Sciences, vol. 59, no. 2, pp. 489-500, 2014.

[19] C. Zhang and N. Lu, "What is the range of soil water density? Critical reviews with a unified model," Reviews of Geophysics, vol. 56, no. 3, pp. 532-562, 2018.

[20] P. A. Mante, C. C. Chen, Y. C. Wen et al., "Probing hydrophilic interface of solid/liquid-water by nanoultrasonics," Scientific Reports, vol. 4, no. 1, pp. 1-6, 2014.

[21] A. C. Jacinto, M. V. Villar, and A. Ledesma, "Influence of water density on the water-retention curve of expansive clays," Géotechnique, vol. 62, no. 8, pp. 657-667, 2012.

[22] Y. Bahramian, A. Bahramian, and A. Javadi, "Confined fluids in clay interlayers: a simple method for density and abnormal pore pressure interpretation," Colloids and Surfaces A: Physicochemical and Engineering Aspects, vol. 521, pp. 260271, 2017.

[23] R. C. Mackenzie, "Density of water sorbed on montmorillonite," Nature, vol. 181, no. 4605, p. 334, 1958.

[24] A. M. Fernandez and P. Rivas, "Analysis and distribution of waters in the compacted FEBEX bentonite: pore water chemistry and adsorbed water properties," Advances in Understanding Engineered Clay Barriers, pp. 257-275, 2005.

[25] X.-Y. Shang, G.-Q. Zhou, L.-F. Kuang, and W. Cai, "Compressibility of deep clay in East China subjected to a wide range of consolidation stresses," Canadian Geotechnical Journal, vol. 52, no. 2, pp. 244-250, 2015.

[26] T. V. Bharat and A. Sridharan, "Prediction of compressibility data for highly plastic clays using diffuse double-layer theory," Clays and Clay Minerals, vol. 63, no. 1, pp. 30-42, 2015.

[27] A. Sridharan, "Soil clay mineralogy and physico-chemical mechanisms governing the fine-grained soil behaviour," Indian Geotechnical Journal, vol. 44, pp. 371-399, 2014.

[28] T. V. Bharat, P. V. Sivapullaiah, and M. M. Allam, "Novel procedure for the estimation of swelling pressures of compacted bentonites based on diffuse double layer theory," Environmental Earth Sciences, vol. 70, no. 1, pp. 303-314, 2013.

[29] S. Tripathy, A. Sridharan, and T. Schanz, "Swelling pressures of compacted bentonites from diffuse double layer theory," Canadian Geotechnical Journal, vol. 41, no. 3, pp. 437-450, 2004.

[30] M. P. Segall, D. E. Buckley, and C. F. M. Lewis, "Clay mineral indicators of geological and geochemical subaerial modification of near-surface Tertiary sediments on the northeastern Grand Banks of Newfoundland," Canadian Journal of Earth Sciences, vol. 24, no. 11, pp. 2172-2187, 1987.

[31] Y. Yukselen and A. Kaya, "Comparison of methods for determining specific surface area of soils," Journal of Geotechnical and Geoenvironmental Engineering, vol. 132, no. 7, pp. 931-936, 2006.

[32] B. Chittoori and A. J. Puppala, "Quantitative estimation of clay mineralogy in fine-grained soils," Journal of Geotechnical and Geoenvironmental Engineering, vol. 137, no. 11, pp. 997-1008, 2011.

[33] S. He, X. Yu, A. Banerjee, and A. J. Puppala, "Expansive soil treatment with liquid ionic soil stabilizer," Transportation Research Record: Journal of the Transportation Research Board, vol. 2672, no. 52, pp. 185-194, 2018.

[34] A. H. Kurichetsky and S. L. Li, The Combination of Soil Water Translation, Geological Publishing House Press, Beijing, China, 1982, in Chinese.

[35] N. Ural, Current Topics in the Utilization of Clay in Industrial and Medical Applications, IntechOpen, London, UK, 2018.

[36] R. D. Holtz and W. D. Kovacs, An Introduction to Geotechnical Engineering, Prentice-Hall, Englewood Cliffs, NJ, USA, 1981.

[37] F. H. Chen, Foundations on Expansive Soils, Elsevier, Amsterdam, Netherlands, 2012.

[38] J. B. Yuan, "The study for properties of bound water on clayey soils and their quantitative methods," M. S. thesis, South China University of Technology, Guangzhou, China, 2012, in Chinese.

[39] S. Li, C. M. Wang, and Q. Wu, "Variations of bound water and microstructure in consolidation-creep process of Shanghai mucky clay," Rock and Soil Mechanics, vol. 38, no. 10, pp. 2809-2816, 2017, in Chinese.

[40] Y. Zhang, T. L. Chen, Y. J. Zhang et al., "Calculation methods of seepage coefficient for clay based on the permeation mechanism," Advances in Civil Engineering, vol. 2019, Article ID 6034526, 9 pages, 2019.

[41] M. V. Villar, "Thermo-hydro-mechanical characterisation of a bentonite from Cabo de Gata: a study applied to the use of bentonite as sealing material in high level radioactive waste 
repositories," Publicación técnica (Empresa Nacional de Residuos Radiactivos), vol. 4, pp. 15-258, 2002.

[42] Y. X. Shao, B. Shi, C. Liu et al., "Temperature effect on hydrophysical properties of clayey soils," Chinese Journal of Geotechnical Engineering, vol. 33, no. 10, pp. 1576-1582, 2011, in Chinese.

[43] J. L. Zheng and R. Zhang, "Prediction and control method for deformation of highway expansive soil subgrade," China Journal of Highway and Transport, vol. 28, no. 3, pp. 1-10, 2015, in Chinese.

[44] J. Ji, W. J. Zhang, F. Zhang et al., "Reliability analysis on permanent displacement of earth slopes using the simplified bishop method," Computers and Geotechnics, vol. 117, 2020.

[45] J. Ji, C. Zhang, Y. Gao, and J. Kodikara, "Reliability-based design for geotechnical engineering: an inverse FORM approach for practice," Computers and Geotechnics, vol. 111, pp. 22-29, 2019.

[46] Y. X. Wu, Y. F. Gao, L. M. Zhang, and J. Yang, "How the distribution characteristics of soil property affect probabilistic foundation settlement: from the view of the first four statistical moments," Canadian Geotechnical Journal, 2019. 